\title{
Utilization of Family Planning Methods and Associated Factors among Women Living with HIV Attending ART Clinics in Nekemte Public Health Facilities, East Wollega Zone, Ethiopia
}

\author{
Alemu Sufa $^{1^{*}}$, Muluemebet Abera $^{2}$ and Bitiya Admasu ${ }^{2}$ \\ ${ }^{* 1}$ College of Medical and Health Sciences, Wollega University, Post Box No: 395, Nekemte, Ethiopia \\ ${ }^{2}$ Department of Reproductive Health, College of Publish Health and Medical Sciences, Jimma University, \\ Jimma, Ethiopa
}

\begin{tabular}{|c|c|}
\hline Abstract & Article Information \\
\hline $\begin{array}{l}\text { This study was designed to assess the utilization of Family planning methods and associated } \\
\text { factors among HIV-infected women in ART clinics of public health institutions Nekemte town, } \\
\text { East Wollega zone, Ethiopia. Facility based cross sectional study design using quantitative } \\
\text { technique of data collection method undertaken from May } 1^{\text {st }} \text { to May } 26^{\text {th }}, 2012 \text {, on a sample of } \\
456 \text { women living with HIV who are on follow up care in ART clinics. Univariate analysis was } \\
\text { done to determine frequencies of FP methods used. Factors associated with use of family } \\
\text { planning methods were examined using logistic regression methods at } p<0.05 \text {. There was a } \\
\text { high level of knowledge about family planning with more than } 98 \% \text { of women knowledgeable of } \\
\text { at least one method used to prevent conception. Out of } 456 \text { respondents } 303(66.4 \%) \text { were } \\
\text { using different methods of family planning during the study period and condom is the dominant } \\
\text { method used by the client ( } 41.6 \% \text { ). High proportion ( } 42.1 \%) \text { of women living with HIVIAIDS } \\
\text { expressed a desire for having more children in the future. Logistic regression result showed } \\
\text { that educational attainment (AOR=3.199, } 95 \% \text { Cl (1.487-6.541), marital status (AOR=95\% CI, } \\
6.252 \text { ( } 4.008-9.752) \text {, and having open discussion with ones partner about family planning } \\
\text { (AOR=95\% Cl, 13.846 (5.062-37.875) were statistically associated with current family planning } \\
\text { use at } p<0.05 \text {. Generally current use of modern contraceptive other than condoms was very low } \\
\text { in the study area. These findings highlight the need for integration of family planning and HIV } \\
\text { care and treatment and strengthening of family planning services for HIV infected people. }\end{array}$ & $\begin{array}{l}\text { Article History: } \\
\text { Received : 11-10-2013 } \\
\text { Revised : 15-12-2013 } \\
\text { Accepted : 27-12-2013 } \\
\text { Keywords: } \\
\text { FP Utilization } \\
\text { PLWHI } \\
\text { East Wollega Zone } \\
\text { ART } \\
\text { HIVIADIS } \\
{ }^{*} \text { Corresponding Author: } \\
\text { Alemu Sufa } \\
\text { E-mail: } \\
\text { alemusufa@ymail.com }\end{array}$ \\
\hline
\end{tabular}

\section{INTRODUCTION}

According to WHO report it was estimated that 1.49 million pregnant women in low and middle income countries were living with the human immunodeficiency virus (HIV). More than $90 \%$ of HIV infections in infants and childrens were passed through mothers during pregnancy, labour, delivery or breastfeeding (WHO, UNAIDS and UNICEF, 2011). Access to antiretroviral therapy in developing countries has improved the life expectancies and health of many PLWH who are resuming sexual activity and often need contraception (WHO, 2007).

Preventing unintended pregnancy among HIV-positive women is an effective approach to reducing pediatric HIV infection and vital to meeting HIV-positive women's sexual and reproductive health needs. Providing contraception to women with HIV who wish to postpone or avoid pregnancy can prevent vertical transmission of HIV from mother to child. Indeed, the prevention of unintended pregnancies among women living with HIV is one of four elements of a comprehensive approach to prevent mother-to-child transmission of HIV (PMTCT) (Ringheim, 2009).

Family Planning (FP) services integrated to preventing primary HIV infection in women have been reported to significantly reduce the proportion of infants infected with HIV by $35 \%-45 \%$ (WHO, 2011). Using contraception for unwanted and unintended births could avert an additional 397 newborn infections as reported in Vietnam and an additional 46,774 in South Africa each year (Reynolds et al. 2008). An estimated 137 million women who want to avoid a pregnancy and they are not using a family planning method in the developing world (USAID, 2009).

In addition to the cost savings incurred by addressing unmet need, greater use of FP services can contribute directly to the MDG goals to reduce child mortality and improve maternal health; family planning helps reduce the number of high-risk pregnancies that result in high levels of maternal and child illness and death (MOFED, 2010). In Ethiopia, mother to child transmission rate is estimated at 
Alemu Sufa et al.,

$30 \%$ in 2011 . In 2011 , approximately 42,900 pregnant women with HIV delivered (UN, 2012). Previous studies in Ethiopia were concentrated on examining factors that influence contraceptive utilization among the general population (Tilahun et al., 2013). Hence, the present study identified the family planning utilization and associated factors among women living with HIV.

\section{MATERIAL AND METHODS}

\section{Study Design and Population}

This study was an institutional based cross sectional study using quantitative data collection method. The study population included a sample of women aged $15-49$ years living with HIV who visited Nekemte Hospital and Health Center during data collection period. Women in a reproductive age group (15-49) and living with HIV, were considered for the study, while those who are critically ill (physically and mentally) to provide informed consent and women who were pregnant during data collection (identified by history and LMP) were excluded from the study.

The sample size was determined by assuming that $50 \%$ of HIV+ individuals may use family planning methods with $5 \%$ marginal error and $95 \% \mathrm{Cl}$ and a none response rate of $20 \%$. Based on this assumption, the actual sample size for the study was determined using the formula for single population proportion and a sample size of 461 was calculated. The calculated sample size was proportionally allocated to the two ART centers found in Nekemte town namely; Nekemte hospital and Nekemte health center based on the total number of client on follow up care in the respective ART centers. Then to select study subjects from each ART unit, systematic sampling was used by referring client's registration book for a day prior to data collection. It is from these numbers that every 3 persons as they registered included in the sample at each ART unit until the required number of sample size was reached.

A structured questionnaire adopted from different literatures were first prepared in english translated in to Afan Oromo and then back translated to english to check for consistency was used to collect information from respondents. The questionnaire was pre- tested in Gimbi Hospital ART unit on $5 \%$ of the total sample size. The questionnaire then assessed for its clarity, length and completeness and some skip patterns were corrected and questions difficult to ask were rephrased.

\section{Data Analysis}

The data cheeked, cleared and entered into SPSS version 16.0 for analysis. The descriptive analysis such as proportions, percentages, frequency distribution and measures of central tendency was used. Initially, bivariable analysis was performed between FP use (dependent variable) and each of the potential factors associated with FP use (independent variables), one at a time. Their odds ratios (OR) at $95 \%$ confidence intervals $(\mathrm{Cl})$ and $p$-values was obtained. The findings at this stage helped us to identify important associations. Then multivariable analysis was performed using the logistic regression model using variables that were significant at $p<0.05$ on bivarate analysis. Factors that were significantly associated with FP use at bivariable analysis were considered in the logistic regression model.
Sci. Technol. Arts Res. J., Oct-Dec 2013, 2(4): 71-77

\section{Ethical Consideration}

Ethical clearance and permission was obtained from Jimma University Ethical Review Committee and permission was secured from Nekemte Hospital and Health centers. Informed consent obtained from each respondent before interview. Confidentiality of individual client information was ensured by use of unique identifiers for study participants and limiting access to the principal investigator and research assistants of study information by storing the completed questionnaires and all documents with participant information in a lockable cabinet.

\section{RESULT}

\section{Socio-demographic Characteristics}

Four hundred sixty one eligible PLWHI selected for the study, 456 agreed to participate giving response rate of $98.9 \%$. The mean age $( \pm S D)$ of the participants was $30.5 \pm 7$ years, age range was $18-48$. Most study respondents were married $279(61.2 \%)$. Three hundred fifty four (77.6\%) were Oromo and 201 (44.1\%) were followers of protestants Christianity. More than half of respondents $267(58.6 \%)$ had primary education. One hundred seventy four (38.2\%) were housewives. Nearly $75 \%$ of the participants were earning monthly income of less than or equal to 500 ETB (Table 1).

Table 1: Socio demographic characteristics of study participant attending ARV treatment units, Nekemte, Ethiopia, May 2012.

\begin{tabular}{|c|c|}
\hline Characteristics $(n=456)$ & Number (\%) \\
\hline \multicolumn{2}{|l|}{ Age } \\
\hline $5-24$ & $90(19.7)$ \\
\hline $25-34$ & $231(50.7)$ \\
\hline $35-44$ & $114(25.0)$ \\
\hline $44+$ & $21(4.6)$ \\
\hline \multicolumn{2}{|l|}{ Marital status } \\
\hline Married & $279(61.2)$ \\
\hline Single & $72(15.8)$ \\
\hline Divorced & $54(11.8)$ \\
\hline Widowed & $51(11.2)$ \\
\hline \multicolumn{2}{|l|}{ Ethnicity } \\
\hline Oromo & $354(77.6)$ \\
\hline Amahara & $75(16.4)$ \\
\hline Gurage & $18(3.6)$ \\
\hline Tigre & $9(2.0)$ \\
\hline \multicolumn{2}{|l|}{ Religion } \\
\hline Orthodox & 165 (36.2) \\
\hline Catholic & $36(7.9)$ \\
\hline Muslim & $54(11.5)$ \\
\hline Protestant & $201(44.1)$ \\
\hline \multicolumn{2}{|l|}{ Educational status } \\
\hline Illiterate & $45(9.9)$ \\
\hline Primary & $267(58.6)$ \\
\hline Secondary & $117(25.7)$ \\
\hline Post-secondary & $27(5.9)$ \\
\hline \multicolumn{2}{|l|}{ Occupational status } \\
\hline Unemployment & $54(11.8)$ \\
\hline House wife & $174(38.2)$ \\
\hline Daily laborers & $34(7.5)$ \\
\hline Government employee & $87(19.1)$ \\
\hline Merchant & $96(21.0)$ \\
\hline Other & $11(2.4)$ \\
\hline \multicolumn{2}{|c|}{$\begin{array}{l}\text { Estimated monthly household } \\
\text { income (in Eth. Birr) }\end{array}$} \\
\hline$\leq 500$ & $348(76.3)$ \\
\hline$>500$ & $108(23.7)$ \\
\hline
\end{tabular}


Alemu Sufa et al.,

HIVIAIDS Diagnosis, Treatment, Care and Support

One hundred eight $(23.7 \%)$ of the respondent had duration of less than or equal to two years since HIV diagnosis. Almost all the study subjects were starting to receive ART drug and the mean duration since HIV diagnosis and receiving ART were 4.6 and 3.3 year, respectively. Of the 279 study participants who were married, 276 (98.9\%) had disclosed their HIV sero-status to their spouse, and the partners of $267(95.7 \%)$ had had an HIV test. Of those with partners who had tested, partners $210(78.7 \%)$, were HIV positive. Four hundred thirty eight $(96.1 \%)$ of the study subjects reported improvement in health status after ART treatment was started. Two hundred sixty seven $(58.6 \%)$ of the respondents said that they have discussed on personal issues such as sexuality, family planning and child bearing with ART providers (Table 2).

Table 2: HIV related characteristics of study participant attending ARV treatment units Nekemte, Ethiopia, May 2012.

\begin{tabular}{|c|c|}
\hline Characteristics & $\begin{array}{c}\text { Number } \\
(\%)\end{array}$ \\
\hline \multicolumn{2}{|c|}{ Duration of HIV diagnosis (in year) ( $n=456)$} \\
\hline Less than or equal to 2 & 108(23.7) \\
\hline Greater than to 2 & $348(76.3)$ \\
\hline \multicolumn{2}{|c|}{ Duration since receiving ART (in year)( $n=456$ ) } \\
\hline Less than or equal to 2 & 192(42.1) \\
\hline Greater than to 2 & 264(57.9) \\
\hline \multicolumn{2}{|c|}{ Disclosure of HIV status to partner $(n=279)$} \\
\hline Yes & 276(98.9) \\
\hline No & $3(1.1)$ \\
\hline \multicolumn{2}{|l|}{ Partner tested for HIV ( $n=279)$} \\
\hline Yes & 267(95.7) \\
\hline No & $12(4.3)$ \\
\hline \multicolumn{2}{|l|}{ Partner HIV status $(n=267)$} \\
\hline Positive & $210(78.7)$ \\
\hline Negative & $57(21.3)$ \\
\hline \multicolumn{2}{|l|}{ Over all health condition after ART ( $n=456)$} \\
\hline Improved & $438(96.1)$ \\
\hline No change & 12(2.6) \\
\hline Deteriorated & $6(1.3)$ \\
\hline \multicolumn{2}{|l|}{$\begin{array}{l}\text { Secured social support from different } \\
\text { group }(n=456)\end{array}$} \\
\hline Yes & $261(57.2)$ \\
\hline No & $195(42.8)$ \\
\hline \multicolumn{2}{|l|}{ Source of support $(n=261)$} \\
\hline Nongovernmental organization & $138(52.9)$ \\
\hline Relative/friend/neighbors & 99(37.9) \\
\hline Governmental organization & $24(9.2)$ \\
\hline \multicolumn{2}{|l|}{ Kind of support ( $n=261)$} \\
\hline Food and health care & $111(42.5)$ \\
\hline Money & $105(40.2)$ \\
\hline Home based care & $45(17.2)$ \\
\hline \multicolumn{2}{|c|}{$\begin{array}{l}\text { Counselor/ART provider discuss about RH issue } \\
(n=456)\end{array}$} \\
\hline Yes & $267(58.6)$ \\
\hline No & 189(41.4) \\
\hline
\end{tabular}

\section{Contraceptive Use and Future Need}

More than $98 \%$ of women were knowledgeable of at least one method used to prevent conception. Majority of women living with HIV $282(61.8 \%)$ had ever used at least one method of contraception before their HIV diagnosis. injectable $129(45.7 \%)$ were the most commonly used contraceptive method before HIV diagnosis.

At the time of the study, out of 456 respondents $303(66.4 \%)$ were using different methods of family planning; of these, (41.6\%) used condoms. Overall, 102
Sci. Technol. Arts Res. J., Oct-Dec 2013, 2(4): 71-77

(33.7\%) of the respondents reported using dual methods (condoms and other FP methods) during the study period. The most common reason for current method choice was health professional's advice $(62.4 \%)$.

Out of 153 respondents who were not using a family planning methods during the study period, 84(54.9\%) wanted to use family planning in the future. In terms of preferred FP methods for future use, the majority $27(32.1 \%)$ still preferred condom. Dual method of contraceptive was intended to be used by about $28.6 \%$ of women who planned to use family planning in the future. Of the 69 respondents who gave reasons as to why no contraceptive need in the future was abstinence from sex $(69.6 \%)$ followed by went to have child in the future (26.1). Out of the study subjects who were using contraceptive during the study period, (21.8\%) did not disclose their HIV status to family planning providers. The most common reason for non-disclosure was fear of stigma and discriminations $(59.1 \%)$. From the 279 respondents with formal relation 255(91.4) were openly discuss about family planning with partner (Table 3 ).

Table 3: Family planning use and need of study participant attending ARV treatment units Nekemte, Ethiopia, May 2012

\begin{tabular}{|c|c|}
\hline Variable & $\begin{array}{c}\text { Number } \\
(\%)\end{array}$ \\
\hline \multicolumn{2}{|l|}{$\begin{array}{l}\text { Knowledge of at least one contraceptive } \\
\text { method }(n=456)\end{array}$} \\
\hline $\begin{array}{l}\text { Yes } \\
\text { No }\end{array}$ & $\begin{array}{c}447(98) \\
9(2)\end{array}$ \\
\hline \multicolumn{2}{|l|}{$\begin{array}{l}\text { Contraceptive ever used prior to } \\
\text { diagnosis }(456)\end{array}$} \\
\hline Yes & 282(61.8) \\
\hline NO & $174(38.2)$ \\
\hline \multicolumn{2}{|l|}{$\begin{array}{l}\text { Contraceptive ever used after } \\
\text { diagnosis }(n=456)\end{array}$} \\
\hline Yes & $360(78.9)$ \\
\hline NO & $96(21.1)$ \\
\hline \multicolumn{2}{|l|}{ Current contraceptive use $(n=456)$} \\
\hline Yes & $303(66.4)$ \\
\hline NO & $153(33.6)$ \\
\hline \multicolumn{2}{|l|}{$\begin{array}{l}\text { Reason for current contraceptive } \\
\text { choose }(n=303)\end{array}$} \\
\hline Health professionals advise & 189(62.4) \\
\hline Perceived saf & $84(27.7)$ \\
\hline From friend experience/advise & $27(8.9)$ \\
\hline Other & $3(1)$ \\
\hline \multicolumn{2}{|l|}{ Future contraceptive need $(n=153)$} \\
\hline Yes & $84(54.9)$ \\
\hline NO & $69(45.1)$ \\
\hline \multicolumn{2}{|l|}{ Reason for non use of FP in the future (69) } \\
\hline Want to have a child & $18(26.1)$ \\
\hline Fear of drug interaction with ART drug & $3(4.3)$ \\
\hline Abstinence from sex & $48(69.6)$ \\
\hline \multicolumn{2}{|l|}{$\begin{array}{l}\text { Disclosure HIV status to contraceptive } \\
\text { service (303) Provider }\end{array}$} \\
\hline Yes & $237(78.2)$ \\
\hline No & $66(21.8)$ \\
\hline \multicolumn{2}{|l|}{ Reason for non disclosure (66) } \\
\hline Fear of stigma and discrimination & $39(59.1)$ \\
\hline Lack of trust on service provider & $15(22.7)$ \\
\hline Other & $9(13.6)$ \\
\hline No response & $3(4.5)$ \\
\hline \multicolumn{2}{|l|}{$\begin{array}{l}\text { Openly share FP use with your sexual } \\
\text { partner (279) }\end{array}$} \\
\hline Yes & 255(91.4) \\
\hline No & $24(8.6)$ \\
\hline
\end{tabular}


The study findings showed that the dominant method of contraceptive used prior to HIV diagnosis was injectable $129(45.7 \%)$. Condom was the commonly used methods

during the study period and intended to be used for the future $126(41.6 \%), 27(32.1 \%)$, respectively (Figure 1 ).

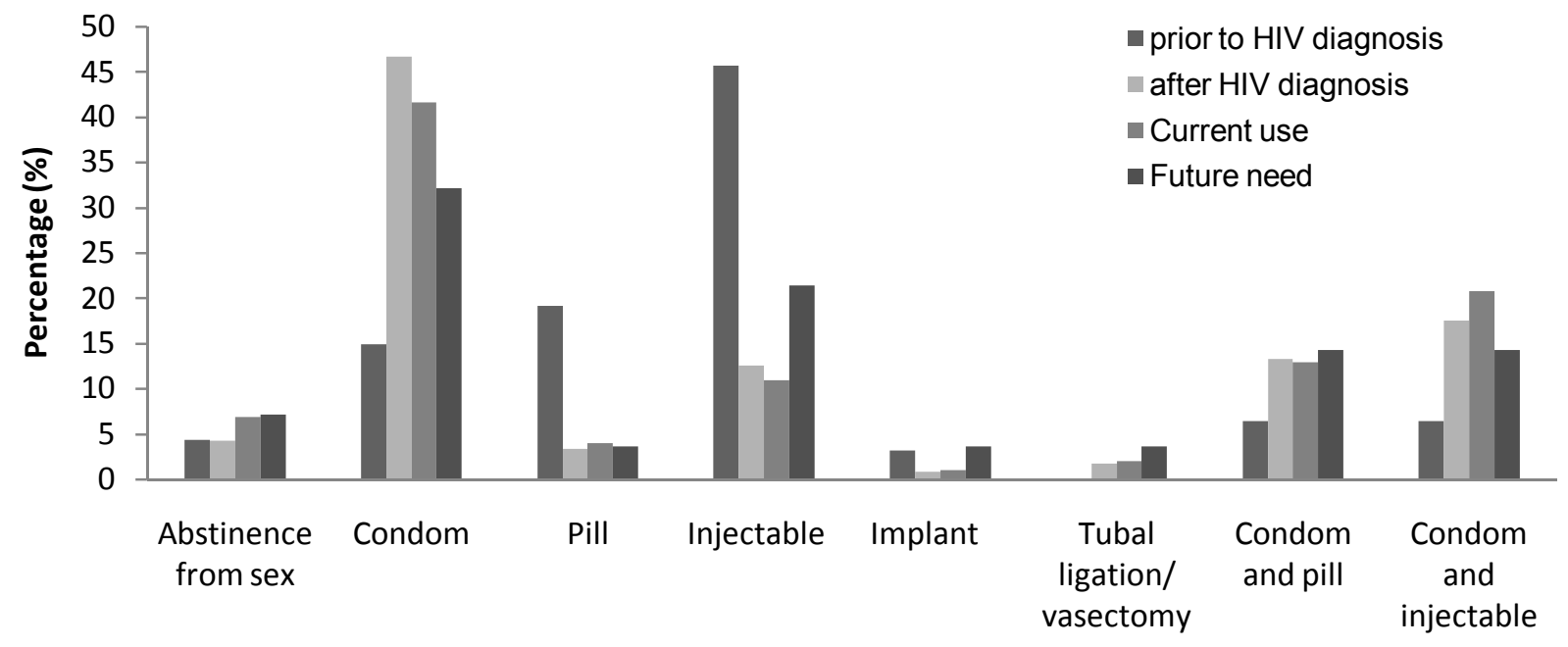

\section{Method of Choice}

Figure 1: Distribution of study participant attending ARV treatment units by methods of contraceptive ever use prior to diagnosis, current use and future need Nekemte, Ethiopia, May 2012.

The commonly preferred site for family planning service delivery was antiretroviral treatment units $(77.7 \%)$ (Figure 2).

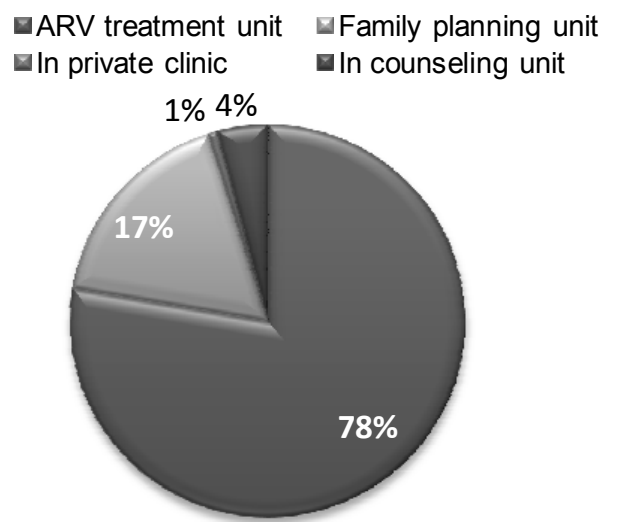

Figure 2: Preferred place for contraceptive service among Study participant attending ARV treatment units Nekemte, Ethiopia, May 2012.

\section{Sexual behavior and condom use}

Majority of about $318(69.7 \%)$ of the study participant were sexually active during the past six months, from which $219(68.9 \%)$ were used condom during sexual practice. Out of those who reported condom use $192(87.7 \%)$ and they used it regularly, while $27(12.3 \%)$ reported irregular use. The most common reason for condom use was advice from health professionals 96 $(43.8 \%)$ whereas the common reason for nonuse of condom during sexual practice was need for more children 35(35.4\%) (Table 4).

\section{Fertility Desire}

While $108(23.7 \%)$ of the study subjects had three and more live births, $75(16.4 \%)$ of the study subjects had three and more children who are currently alive. One hundred ninety two $(42.1 \%)$ of the respondents expressed
Table 4: Sexual behavior and condom use of study participant attending ARV treatment units Nekemte, Ethiopia, May 2012.

\begin{tabular}{|c|c|}
\hline Characteristics & $\begin{array}{c}\text { Number } \\
(\%)\end{array}$ \\
\hline \multicolumn{2}{|l|}{$\begin{array}{l}\text { Sexually active in the past } 6 \text { month } \\
(n=456)\end{array}$} \\
\hline Yes & $318(69.7)$ \\
\hline NO & $138(30.3)$ \\
\hline \multicolumn{2}{|l|}{ Used condom $(n=318)$} \\
\hline Yes & $219(68.9)$ \\
\hline No & $99(31.1)$ \\
\hline \multicolumn{2}{|l|}{ How often used condom (219) } \\
\hline Always & $192(87.7)$ \\
\hline Sometimes & $27(12.3)$ \\
\hline \multicolumn{2}{|l|}{ Reason for condom use $(n=219)$} \\
\hline To prevent pregnancy & $93(42.5)$ \\
\hline Partners HIV status is negative & $18(8.2)$ \\
\hline Health care provider advice & $96(43.8)$ \\
\hline Other & $12(5.5)$ \\
\hline \multicolumn{2}{|l|}{ Reason for non use of condom ( $n=99)$} \\
\hline Partner dislike to use condom & $31(31.3)$ \\
\hline Want to have children & $35(35.4)$ \\
\hline Other & $18(18.2)$ \\
\hline No response & $15(15.2)$ \\
\hline
\end{tabular}

the future desire for children. Out of those desired to have children $185(96.4 \%)$ desired to have less than two and equal to two children. One hundred sixty two (84.4\%) of the study subjects who desire to have children planned to have a child within two years period. Out of the 264 respondents who are not desired to have children in the future the major reason given were have desired number of children $111(42 \%)$. Out of 279 respondents with partner $162(58.1 \%)$ of their spouse expressed desire to have children in the future. Majority of the respondents 210(46.1) pointed out that ART/PMTCT increased their fertility desire (Table 5). 
Table 5: Distribution of study participant attending ART service by fertility desire at ARV treatment units Nekemte, Ethiopia, May 2012.

\begin{tabular}{|c|c|}
\hline Characteristics & $\begin{array}{l}\text { Number } \\
(\%)\end{array}$ \\
\hline \multicolumn{2}{|l|}{ Number of live birth $(n=456)$} \\
\hline 0 & 138(30.3) \\
\hline $1-2$ & $210(46.1)$ \\
\hline$>=3$ & $108(23.7)$ \\
\hline \multicolumn{2}{|l|}{ Number of current live birth $(n=456)$} \\
\hline 0 & $150(32.9)$ \\
\hline $1-2$ & $231(50.7)$ \\
\hline$>=3$ & $75(16.4)$ \\
\hline \multicolumn{2}{|l|}{ Plan to have child in the future $(n=456)$} \\
\hline Yes & 192(42.1) \\
\hline No & 264(57.9) \\
\hline \multicolumn{2}{|l|}{$\begin{array}{l}\text { When do you prefer to have children? } \\
(n=192)\end{array}$} \\
\hline $1-2$ year & $162(84.4)$ \\
\hline$>2$ year & $30(15.6)$ \\
\hline \multicolumn{2}{|l|}{$\begin{array}{l}\text { Number of children you plan to have } \\
\text { (192) }\end{array}$} \\
\hline $1-2$ & $185(96.4)$ \\
\hline$>2$ & $7(3.6)$ \\
\hline \multicolumn{2}{|l|}{$\begin{array}{l}\text { Reason not to have children in the } \\
\text { future (264) }\end{array}$} \\
\hline Have desired number of children & $111(42)$ \\
\hline Fear of MTCT & $81(30.7)$ \\
\hline Lack of adequate income & $54(20.5)$ \\
\hline Other & $18(6.8)$ \\
\hline \multicolumn{2}{|l|}{ Partner desires to have children $(n=279)$} \\
\hline Yes & 162(58.1) \\
\hline NO & $117(41.9)$ \\
\hline \multicolumn{2}{|l|}{$\begin{array}{l}\text { Contribution of ART/PMTCT on fertility } \\
\text { desire (456) }\end{array}$} \\
\hline Yes & $210(46.1)$ \\
\hline No & 246(53.9) \\
\hline
\end{tabular}

\section{Factors Associated with Current Use of Family Planning}

In a multivariate analysis educational status of woman living with HIV displayed significant positive relationships with a woman's odds of utilizing a family planning service $(p<0.05)$. Relative to women with no education, women with some form of education had significantly greater odds of utilizing a family planning service (AOR=3.199, 95\%, Cl 1.487-6.541).

On further multivariate analysis age of respondent, knowledge on family planning didn't show significant association with current utilization of family planning. The finding of the study identified that discussion of reproductive health issues with partner including family planning have strong statistical association with current family planning practice $(p<0.001)$. In multivariate analysis those women who were discussed about family planning issues with spouse were significantly greater odds of utilizing family planning compared to non-discussant $(A O R=13.846,95 \%, \mathrm{Cl}, 5.062-37.875)$ (Table 6).

\section{DISCUSSION}

Family planning use is important for HIV positive individuals like any HIV negative people to space and limit birth and to prevent unintended pregnancy irrespective of their fertility desire. Furthermore, avoiding unintended pregnancy among HIV positive women is one way of vertical HIV transmission reduction and prevention strategies as outlined by WHO (2002).

In this study knowledge of at least one method of contraception is nearly universal among the studied subjects $(98.8 \%)$. This figure is similar to the finding reported by EDHS, 2011 in Ethiopia, which was 97\% (CSA, 2011).

Over half $(66.4 \%)$ of the sexually active women who seek care and support from Nekemte Hospital and Health Center ART clinic were currently using some form of family planning method. The findings show that current use of family planning methods among HIV-infected individuals in Nekemte ART unit was higher than that of reported in the general population in Ethiopia and Oromia region (9\% and $26 \%$ ) respectively (CSA, 2011). One possible reason for this difference could be the difference in reference populations. The national prevalence was based on data from the general population of married women not necessarily receiving routine FP counseling while the prevalence from this study was based on a cohort of PLWHIV receiving routine FP counseling and provided with free condoms. Another possible reason for the high CPR of family planning among this population was due to high condom use rates since condoms are important for dual protection. This figure is lower than that reported from USA in which $(90 \%)$ and much higher than a study result reported from Lesotho Demographic and Health Survey (34\%) (Stanwood et al., 2007; Adair, 2009).

Majority $(62.4 \%)$ of the study participant pointed out that, the health care provider's advice was the main reason for current family planning choice and use. From those who was not using family planning during the study period majority plan to use family planning in the future. The result of the study is much higher than finding from north Nigeria where only $17 \%$ of currently non users of family planning have intention to use family planning in the future (Zubairu et al., 2009). The reason for existing discrepancy might be improved family planning counseling in the study setting. The most preferred family planning service delivery site is ARV treatment unit $282(77.7 \%)$ which has programmatic implication that the clients need to get the family planning services along with their HIV care and treatment unit.

In this study, $78.2 \%$ of the study participants had discussed family planning with health workers. It was higher than the proportion of PLWHIV that were discussed family planning with health care provider in Ethiopia and Uganda (59\%) (Menberu et al., 2010; Barbara et al., 2011). FP counseling is quite important in correction of myths and misconceptions related to FP use, creating awareness of the various FP options for PLWHIV to make their preferred choices of FP methods, and in addressing other FP related barriers. A much higher proportion of respondents $91.4 \%$ were openly discussed about family planning and fertility related factors with their spouse, whereas the finding from Uganda showed that only $62.6 \%$ of the respondents discussed about the issue with their spouse (Barbara et al., 2011). 
Table 6: Logistic regration showing the association of current use of family planning by selected characteristics among study participant attending ART treatment units Nekemte, Ethiopia, May 2012.

\begin{tabular}{|c|c|c|c|c|}
\hline \multirow[t]{2}{*}{ Variables } & \multicolumn{2}{|c|}{ Current FP utilization } & \multicolumn{2}{|c|}{$95 \% \mathrm{Cl}$} \\
\hline & Yes & No & COR & AOR \\
\hline \multicolumn{5}{|l|}{ Age category } \\
\hline $15-24$ & $69(76.7)$ & $21(23.3)$ & 1 & \\
\hline $25-34$ & $150(64.9)$ & $81(35.1)$ & $0.564(0.323-0.985)$ * & \\
\hline $35-44$ & $72(63.2)$ & $42(36.8)$ & $0.522(0.281-0.969)$ * & \\
\hline $44+$ & $12(57.1)$ & $9(42.9)$ & $0.406(0.150-1.095)$ & \\
\hline \multicolumn{5}{|l|}{ Educational status } \\
\hline Illiterate & $21(46.7)$ & $4(53.3)$ & 1 & 1 \\
\hline Literate & $282(68.6)$ & $129(31.4)$ & 2. $498(1.342-4.652)$ & $3.199(1.487-6.541)$ * \\
\hline \multicolumn{5}{|l|}{ Knowledge about FP } \\
\hline Yes & $300(67.1)$ & $147(32.9)$ & $4.082(1.007-16.550)$ * & \\
\hline NO & $3(33.3)$ & $6(66.7)$ & 1 & \\
\hline \multicolumn{5}{|l|}{ Marital status } \\
\hline Married & $25(80.6)$ & $54(19.4)$ & $5.288(3.475-8.048)$ ** & $6.252(4.008-9.752) * *$ \\
\hline Single/divorced/widowed & $78(44.1)$ & $99(55.9)$ & 1 & \\
\hline \multicolumn{5}{|l|}{ Income } \\
\hline$\leq 500$ & $225(64.7)$ & $30(27.8)$ & 1 & \\
\hline$>500$ & $78(72.2)$ & $123(35.3)$ & $1.421(0.884-2.285)$ & \\
\hline \multicolumn{5}{|l|}{ Fertility desire } \\
\hline Yes & $132(68.8)$ & $60(31.2)$ & $1.196(0.805-1.778)$ & \\
\hline No & $171(64.8)$ & $93(35.2)$ & 1 & \\
\hline \multicolumn{5}{|l|}{ Number of alive children } \\
\hline 0 & $93(62)$ & $57(38)$ & 1 & \\
\hline $1-2$ & $162(70.1)$ & $69(29.9)$ & $1.439(0.933-2.220)$ & \\
\hline$>=3$ & $48(64)$ & $27(36)$ & $1.090(0.613-1.937)$ & \\
\hline \multicolumn{5}{|l|}{$\begin{array}{l}\text { Openly share FP } \\
\text { use with Partner }\end{array}$} \\
\hline Yes & $216(84.7)$ & $39(15.3)$ & $9.231(3.776-22.568)$ ** & $13.846(5.062-37.875)$ ** \\
\hline NO & $9(37.5)$ & $15(62.5)$ & 1 & 1 \\
\hline \multicolumn{5}{|l|}{ Partner sero-status } \\
\hline Positive & $168(80)$ & $42(20)$ & 1 & \\
\hline Negative & $45(78.9)$ & $12(21.1)$ & $0.938(0.456-1.928)$ & \\
\hline
\end{tabular}

Three hundred three $(66.4 \%)$ respondents reported that they were currently using a family planning method, as compared to $61.8 \%$ before HIV diagnosis. The most commonly used family planning method before HIV diagnosis was injectable compared to condoms after diagnosis. The finding aggress with study result done on correlates of fertility intentions among HIVIAIDS patients in Northern Nigeria which shows that after HIV diagnosis clients were using different methods of family planning of these, $65(19.4 \%)$ used condoms, while $8(2.4 \%)$ used oral contraceptive pills and only $2(0.6 \%)$ practiced abstinence (Zubairu et al., 2009). The high proportion of condom use as a contraceptive prevalence may be related to the promotion of condoms among PLWHIV and the public as a dual method to protect from unwanted pregnancy and STI/HIV transmission.

This study found that a high proportion $(42.1 \%)$ of women living with HIVIAIDS and $58.1 \%$ of their partner expressed a desire for having more children. This figure is lower than that reported from Ethiopian EDHS 2011(57\%) and northeast Nigeria showed that One hundred and sixty seven females $(65.5 \%)$ and $52(61.2 \%)$ males expressed the desire to have more children (CSA, 2011 and Zubairu, et al., 2009). However, it was higher than the proportion of PLWHI that were desirous of reproduction in Kenya (18\%) and rural Uganda (7\%) (Horizons, 2005 and Rhoda, 2011) and Ethiopia (30.7\%) (Tesfaye Regassa and Mesganaw
Fantahun, 2012). The finding showed that being HIV positive modified but did not remove reproductive desires, and diversity existed in reproductive intentions.

From those desired to have children in the future large proportion $96.4 \%$ of the participant desire to have one to two children and about $15.6 \%$ want to wait for more than two year. The result is much higher than that reported from Northern Nigeria, here more than half of them want to have less than or equal to two children (Zubairu, 2009).

In multivariate analysis, educational level and marital status were identified as important predictors of current family planning use among the study participants. Similar study conducted in Uganda on assessment of contraception among persons living with HIV attending HIV care and support center shows that, the education level and marital status were significantly associated with contraceptive use (Othman et al., 2010). Finding from EDHS (2011) also confirmed that current contraceptive use increases with women's educational attainment (CSA, 2011). It is thought that increased educational attainment operates through a multiple mechanisms in order to influence service use, including increasing female decision-making power on reproductive health particularly family planning. 
Alemu Sufa et al.,

Discussion on family planning with approval of one's spouse and FP use were statistically significant at multivariate analysis and where the odds of family planning utilization were higher among women who have open discussion about family planning with partner than their counterparts $(p<0.001)$. These findings were comparable with the study among women regardless of HIV status by Rob et al. (2007), showed partner approval was more likely to be associated with use of modern contraceptive in six countries that included Kenya, Malawi, Tanzania, Ivory Cost, Burkina Faso and Ghana (Rob et al., 2007). Men often play decisive roles in either supporting or hindering the use of contraceptives by their spouses or partners thus communication with partner is vital to remove challenges such as partner opposition in making fertility related decisions. Men should also be part of a programmatic response to prevent unintended pregnancies among women with HIV.

\section{CONCLUSIONS}

In conclusion, the majority of PLWHIV seeking care and treatment from Nekemte public ART centers reported current use of some method of family planning. Condoms were the most frequently reported family planning method. Current use of modern contraceptive other than condoms was very low in the study area. Large portions of the HIVpositive women in the study were, desired to have children. Educational attainment, marital status and partner communication about the issue of family planning was significant predictors of family planning use among study participants.

\section{ACKNOWLEDGEMENTS}

We would like to express our deepest gratitude and appreciation to Jimma University for facilitating this research and the management and staff members of Nekemte Hospital and Health Centre service centre where this research was carried out. We are also grateful to supervisor and data collectors who committed themselves throughout the study period. Finally, we would like to express our gratitude to all participants who participated in the study.

\section{REFERENCES}

Adair, T. (2009). Unmet need for contraception among HIV-positive women in lesotho and implications for mother-to-child transmission. Journal of Biosocial Science 41(2): 269-278.

Barbara, N., Jianghong, L., Sandra, C., Thompson, B., Christopher, G., Orach, K. (2011). Family planning among people living with HIV in post-conflict Northern Uganda: A mixed methods study. Conflict and Health 5(18): 1-12.

Central Statistical Agency (CSA), ORC Macro, Calverton, Maryland and USA. (2012). Ethiopia Demographic and Health Survey 2011. Addis Ababa, Ethiopia.

Joint United Nations Programme on HIVIAIDS (2012), Together We Will End AIDS.

Menberu, G., Fessehaye, A., Mulumebet, A., Amare, D. (2010). Factors affecting fertility decisions of married men and women living with HIV in SouthWollo Zone, Northeast Ethiopia. Ethiopian Journal of Health Development 24(3): 214-220.
Sci. Technol. Arts Res. J., Oct-Dec 2013, 2(4): 71-77

MOFED (2010). Ethiopian millennium development goals report. Trend and prospects for meeting MDGs by 2015 Ministry of finance and economic development (MOFED).

Othman, K., Dan, K and Michael, H. (2010). Contraception among persons living HIV with infection attending an HIV care and support centre in Kabale, Uganda. Journal of Public Health and Epidemiology 2 (8), 180-188.

Reynolds, H.W., Janowitz, B., Wilcher, R. (2008). Contraception to prevent HIV-Positive births: current contribution and potential cost savings in PEPFAR Countries. Sexually Transmitted Infections 84(4): 120330

Rhoda, K., Nazarius, M., Rosemary, K., Jolly, B., Lynn, A., Stella, N. (2011). Uptake of family planning methods and unplanned pregnancies among HIV-infected individuals: a cross-sectional survey among clients at HIV clinics in Uganda. Journal of the International AIDS Society 14: 35-45.

Ringheim, K. (2009). Five Good Reasons to Integrate Family Planning/ Reproductive Health and HIV Services.

Rob, S., Baschieri, A., Steve, C., Monique H., Nyovani, M. (2007). Contextual Influences on Modern Contraceptive Use in Sub-Saharan Africa. American Journal of Public Health 8(5): 345-623.

Stanwood, N.L., Cohn, S.E., Heiser, J.R., Pugliese, M., Contraception and fertility plans in a cohort of HIVpositive women in care. Contraception 75(4): 294-298.

Tesfaye Regassa and Mesganaw Fantahun, (2012). Fertility Desire and Reproductive Health Care Needs of Men and Women Living with HIVIAIDS in Nekemte, East Wollega, Ethiopia. Science, Technology and Arts Research Journal 1(3): 31-38.

Tilahun, T., Coene, G., Luchters, S., Kassahun, W., Leye, E., Temmerman, M., Degomme, O. (2013) Family Planning Knowledge, Attitude and Practice among Married Couples in Jimma Zone, Ethiopia. PLOS ONE 8(4): e61335.

USAID (2009). Briefing paper. The Status of Family Planning in sub-Saharan Africa. Geneva.

WHO (2002). Strategic approaches to the prevention of HIV infection in infants: Report of a WHO meeting. Morges, Switzerland, 20-22 March. Geneva.

WHO (2006). Sexual and reproductive health of women living with HIVIAIDS. Geneva.

WHO (2007). "Prevention of Mother-to-Child Transmission of HIV," HIV Technical Briefs. Geneva.

WHO, UNAID and UNICEF (2011). Global HIVIAIDS response: epidemic update and health sector progress towards universal access: progress report 2011, Geneva.

Zubairu, I., Abubakar, S., Mohammed, K., Musa, B., Faisal, S., Muktar, H. (2009). Correlates of Fertility Intentions among HIVIAIDS Patients in Northern Nigeria, African Journal of Reproductive Health 13(30): 71-83. 